\title{
Construct Validity of the Two-Factor Revised Learning Process Questionnaire in a Singapore High School
}

\author{
Chiu Wai Chow ${ }^{1,2} \&$ Elaine Chapman ${ }^{1}$ \\ ${ }^{1}$ Graduate School of Education, The University of Western Australia, Perth, Australia \\ ${ }^{2}$ Hwa Chong Institution, Singapore \\ Correspondence: Chiu Wai Chow, Education Technology Department, Hwa Chong Institution, 661 Bukit Timah \\ Road, 269734, Singapore. E-mail: chowcw@hci.edu.sg
}

Received: December 12, 2017 Accepted: Janury 2, 2017 Online Published: September 11, 2018

doi:10.5539/jedp.v8n2p159

URL: http://doi.org/10.5539/jedp.v8n2p159

\begin{abstract}
The Revised Two-factor Learning Process Questionnaire (R-LPQ-2F) is an instrument for assessing students' learning approaches at the high school level. The instrument has significant potential for use in Singapore schools, but as yet, has not been validated in this context. This study evaluated the validity attributes of the R-LPQ-2F in a sample of Singapore senior high school students. The sample comprised 455 Year 11 students (266 male, 189 female) from Singapore. The internal structure of the R-LPQ-2F was evaluated by replicating the confirmatory factor analyses published in previous validations of the instrument, and assessing its internal consistencies and inter-scale correlations. Relationships between the R-LPQ-2F subscales and external variables were also evaluated. Results indicated that for the Deep Approach scale, a one-factor model fit the data well. For the Surface Approach scale, a four-factor model (Fear of Failure; Aim for Qualification; Minimizing Scope of Study; and Memorization) was found to fit the data best. Correlations between scores on the R-LPQ-2F subscales, on the Motivated Strategies for Learning Questionnaire, and a physics achievement test demonstrated expected patterns of correlation. Overall, results obtained in this study supported the construct validity of the R-LPQ-2F for use with Singapore high school students.
\end{abstract}

Keywords: learning, R-LPQ-2F, Singapore schools

\section{Introduction}

Recent decades have witnessed a growing interest in the approaches that students adopt when undertaking their learning tasks (Biggs, 1999; Marton, Hounsell \& Entwistle, 1997; Marton \& Säljö, 1976). In general, research in this field has focused on two distinct types of learning approach: deep and surface (Biggs \& Tang, 2007; Entwistle, 1988; Marton \& Säljö, 1976). Students who adopt a deep approach to learning are depicted as those who focus on internalizing new information, connecting new understandings with existing knowledge, and analyzing how new concepts can be applied across different situations. In contrast, students who adopt a surface approach to learning are depicted as those who focus on memorizing and reproducing information, paying less attention to understanding or applying what they have learned.

Previous studies have indicated a positive relationship between deep approaches to learning and cognitive development (e.g., Nelson Laird et al., 2007; Phan, 2007, 2011). In a recent large-scale study involving 22,000 students across 30 high schools in the United States, it was found that students who adopted a deep approach to learning demonstrated higher levels of content mastery and problem-solving skills than those who adopted more surface-based approaches (O’Day \& Garet, 2014). Other research has also indicated that students who adopt a deep approach to learning tend to report higher levels of enjoyment and fulfilment in the process of learning than those who adopt a surface approach (e.g., Biggs \& Tang, 201; Ramsden, 2003).

Traditionally, Asian learners have been perceived to rely heavily on surface approaches to learning (Pratt \& Wong, 1999; Samuelowicz, 1987). While this viewpoint has been contested (Biggs, 1987; Kember \& Gow, 1991; Watkins \& Biggs, 1996), various government agencies in Asia have responded to such concerns through initiatives to discourage the use of surface learning methods by students. For example, in 1997, the Singapore Ministry of Education (MOE) reviewed its curriculum and assessment systems and proposed that schools should adopt methods that promote deep learning approaches, and, in so doing, develop students' critical and inventive thinking 
skills (Goh, 1997). This remained an emphasis in the Singapore MOE's (2006) Teach Less Learn More initiative, as well its more recent (2010) $21^{\text {st }}$ Century Competency Framework (Rajah, 2013).

In order to monitor the efficacy of such initiatives, valid and reliable measures of students' learning approaches are needed. At the high school level, the Learning Process Questionnaire (LPQ: Biggs, 1987) has been used for such a purpose (e.g., Campbell et al., 2001; Cano, 2005). The original LPQ comprised three main learning approach scales: deep, surface, and achieving. The term 'achieving approach' was used to refer to strategies adopted by students to maximize academic performance (Biggs, 1987). In a subsequent revision of the LPQ (Kember, Biggs \& Leung, 2004), the achieving scale was removed due to its significant overlap with the deep and surface approach scales. This revision, labelled the Revised Two-Factor Learning Process Questionnaire (R-LPQ-2F), also included a reduced number of items to make the instrument more practical to administer in the classrooms.

Each of the two main R-LPQ-2F scales (Deep Approach and Surface Approach) comprises a motive and a strategy subscale, producing four subscales in all (Deep Motive, Deep Strategy, Surface Motive and Surface Strategy). Within each subscale, there are two further components. In total, the R-LPQ-2F comprises 22 item statements, to which students respond on a five-point scale ('never or only rarely true of me' to 'always or almost always true of me'). The score for each scale, subscale and component are typically computed by taking the average of their corresponding item scores. Thus, the scores range from 1 (never or only rarely true of me) to 5 (always or almost always true of me).

Table 1. Structure and items in the R-LPQ-2F

\begin{tabular}{|c|c|c|c|c|}
\hline Scale & Subscale & Component & & Item Statement \\
\hline \multirow{11}{*}{$\begin{array}{l}\text { Deep } \\
\text { Approach }\end{array}$} & \multirow{7}{*}{$\begin{array}{l}\text { Deep } \\
\text { Motive }\end{array}$} & \multirow{3}{*}{ Intrinsic Interest } & & $\begin{array}{l}\text { (1) I find that at times studying makes me feel really happy and } \\
\text { satisfied. }\end{array}$ \\
\hline & & & & $\begin{array}{l}\text { (5) I feel that nearly any topic can be highly interesting once I get into } \\
\text { it. }\end{array}$ \\
\hline & & & & (9) I work hard at my studies because I find the material interesting. \\
\hline & & \multirow{4}{*}{$\begin{array}{l}\text { Commitment } \\
\text { Work }\end{array}$} & \multirow{4}{*}{ to } & $\begin{array}{l}\text { (13) I spend a lot of my free time finding out more about interesting } \\
\text { topics which have been discussed in different classes. }\end{array}$ \\
\hline & & & & $\begin{array}{l}\text { (17) I come to most classes with questions in mind that I want } \\
\text { answering. }\end{array}$ \\
\hline & & & & $\begin{array}{l}\text { (19) I find I am continually going over my school work in my mind at } \\
\text { times like when I am on the bus, walking, or lying in bed, and so on. }\end{array}$ \\
\hline & & & & $\begin{array}{l}\text { (21) I like to do enough work on a topic so that I can form my own } \\
\text { conclusions before I am satisfied. }\end{array}$ \\
\hline & \multirow{4}{*}{$\begin{array}{l}\text { Deep } \\
\text { Strategy }\end{array}$} & \multirow{2}{*}{\multicolumn{2}{|c|}{ Relating Ideas }} & $\begin{array}{l}\text { (2) I try to relate what I have learned in one subject to what I learn in } \\
\text { other subjects. }\end{array}$ \\
\hline & & & & (6) I like constructing theories to fit odd things together. \\
\hline & & \multirow{2}{*}{\multicolumn{2}{|c|}{ Understanding }} & $\begin{array}{l}\text { (10) I try to relate new material, as I am reading it, to what I already } \\
\text { know on that topic. }\end{array}$ \\
\hline & & & & $\begin{array}{l}\text { (14) When I read a textbook, I try to understand what the author } \\
\text { means. }\end{array}$ \\
\hline
\end{tabular}


Table 1. Structure and items in the R-LPQ-2F (Continued)

\begin{tabular}{|c|c|c|c|c|}
\hline Scale & Subscale & \multicolumn{2}{|l|}{ Component } & Item Statement \\
\hline \multirow{11}{*}{$\begin{array}{l}\text { Surface } \\
\text { Approach }\end{array}$} & \multirow{4}{*}{$\begin{array}{l}\text { Surface } \\
\text { Motive }\end{array}$} & \multirow{2}{*}{\multicolumn{2}{|c|}{ Fear of Failure }} & $\begin{array}{l}\text { (3) I am discouraged by a poor mark on a test and worry about how I } \\
\text { will do on the next test. }\end{array}$ \\
\hline & & & & $\begin{array}{l}\text { (7) Even when I have studied hard for a test, I worry that I may not be } \\
\text { able to do well in it. }\end{array}$ \\
\hline & & \multirow{2}{*}{\multicolumn{2}{|c|}{$\begin{array}{l}\text { Aim } \\
\text { Qualification }\end{array}$}} & $\begin{array}{l}\text { (11) Whether I like it or not, I can see that doing well in school is a } \\
\text { good way to get a well-paid job. }\end{array}$ \\
\hline & & & & $\begin{array}{l}\text { (15) I intend to get my A Levels because I feel that I will then be able } \\
\text { to get a better job. }\end{array}$ \\
\hline & \multirow{7}{*}{$\begin{array}{l}\text { Surface } \\
\text { Strategy }\end{array}$} & \multirow{4}{*}{$\begin{array}{l}\text { Minimizing } \\
\text { of Study }\end{array}$} & \multirow{4}{*}{ Scope } & $\begin{array}{l}\text { (4) I see no point in learning material which is not likely to be in the } \\
\text { examination. }\end{array}$ \\
\hline & & & & $\begin{array}{l}\text { (8) As long as I feel I am doing enough to pass, I devote as little time } \\
\text { to studying as I can. There are many more interesting things to do. }\end{array}$ \\
\hline & & & & $\begin{array}{l}\text { (12) I generally restrict my study to what is specifically set as I think it } \\
\text { is unnecessary to do anything extra. }\end{array}$ \\
\hline & & & & $\begin{array}{l}\text { (16) I find it is not helpful to study topics in depth. You don't really } \\
\text { need to know much in order to get by in most topics. }\end{array}$ \\
\hline & & \multirow{3}{*}{\multicolumn{2}{|c|}{ Memorization }} & $\begin{array}{l}\text { (18) I learn some things by rote, going over and over them until I know } \\
\text { them by heart. }\end{array}$ \\
\hline & & & & $\begin{array}{l}\text { (20) I find the best way to pass examinations is to try to remember } \\
\text { answers to likely questions. }\end{array}$ \\
\hline & & & & $\begin{array}{l}\text { (22) I find I can get by in most assessment by memorising key sections } \\
\text { rather than trying to understand them. }\end{array}$ \\
\hline
\end{tabular}

Despite the potential utility of the R-LPQ-2F for assessing students' learning approaches, only two studies have been published to date on its psychometric properties at the high school level. The first was published by the authors of the revised version (Kember et al., 2004), and was based on a sample of 841 Hong Kong senior high school students. Results of the first-order confirmatory factor analyses performed in this study are presented in Table 2. Only models using item scores as observed variables are included here, as those using component scores as observed variables can produce very different results (e.g., Bandalos \& Finney, 2001). As indicated, fit indices for the two-factor model (i.e., Model I: Deep Approach and Surface Approach) were adequate. Separate confirmatory factor analyses (CFAs) were also conducted for the four components of the Deep Approach and for the four components of the Surface Approach (i.e., Models IIa and IIb in Table 2, respectively), and both produced excellent fit indices. While the Cronbach's $\alpha$ s for the overall Deep and Surface Approach scales were acceptable ( 0.82 and 0.71 respectively), values for the individual components within these scales were low, ranging from 0.48 to 0.70 . Five of the eight components fell below the commonly accepted 0.60 level (Kline, 2000). The internal consistencies of the four subscales, however, ranged from 0.58 to 0.75 , with only one (i.e., Surface Motive) falling just below the 0.60 level. The latter result was attributed to the multidimensionality of this particular subscale (Biggs, 1993). 
Table 2. Fit indices reported by Kember et al. (2004) and Phan and Deo (2007)

\begin{tabular}{|c|c|c|c|}
\hline \multirow{2}{*}{ Model } & \multirow{2}{*}{ Latent Factors } & \multicolumn{2}{|l|}{ Fit Indices } \\
\hline & & Kember et al. (2004) & Phan \& Deo (2007) \\
\hline (I) Two-factor & $\begin{array}{l}\text { First-order factors: } \\
\text { - } \quad \text { Deep Approach } \\
\text { - } \quad \text { Surface Approach }\end{array}$ & $\begin{array}{l}\mathrm{CFI}=0.804 \\
\mathrm{SRMR}=0.049\end{array}$ & $\begin{array}{l}\mathrm{CFI}=0.80 \\
\mathrm{NNFI}=0.78 \\
\text { RMSEA }=0.06\end{array}$ \\
\hline (IIa) Four-factor (Deep) & $\begin{array}{l}\text { First-order factors: } \\
\text { - } \quad \text { Intrinsic Interest } \\
\text { - } \quad \text { Commitment to Work } \\
\text { - } \quad \text { Relating Ideas } \\
\text { - } \quad \text { Understanding }\end{array}$ & $\begin{array}{l}\mathrm{CFI}=0.969 \\
\mathrm{SRMR}=0.027\end{array}$ & $\begin{array}{l}\text { CFI }=0.95 \\
\text { NNFI }=0.93 \\
\text { RMSEA }=0.05\end{array}$ \\
\hline (IIb) Four-factor (Surface) & 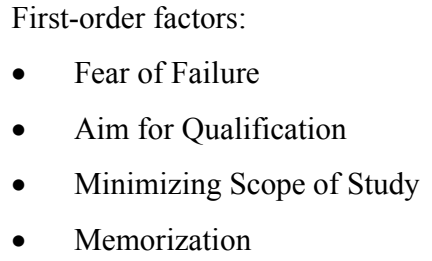 & $\begin{array}{l}\mathrm{CFI}=0.965 \\
\mathrm{SRMR}=0.024\end{array}$ & $\begin{array}{l}\mathrm{CFI}=0.85 \\
\mathrm{NNFI}=0.84 \\
\text { RMSEA }=0.06\end{array}$ \\
\hline
\end{tabular}

The only other validity study of the R-LPQ-2F that could be located which involved a high school sample was conducted by Phan and Deo (2007). They replicated Kember et al.'s (2004) analysis using a sample of 2295 students from 35 high schools in the Fiji islands. Results for this study are also summarized in Table 2. As indicated, the fit indices of the two-factor model (i.e., Model I: Deep Approach and Surface Approach) were again adequate, though the NNFI was somewhat low. The separate CFAs conducted for the four components of the Deep and Surface Approach scales (i.e., Models IIa and IIb in Table 2, respectively) produced better fits to the data, similar to the results obtained by Kember et al. (2004). However, Cronbach's $\alpha$ values were somewhat lower than those obtained in Kember et al.'s study. While the as for the Deep and Surface Approach scales as a whole were acceptable (0.70 and 0.62, respectively), the $\alpha$ for all four of the subscales (i.e., Deep Motive, Deep Strategy, Surface Motive, and Surface Strategy) fell below 0.60. Internal consistencies were not reported for the eight individual subscale components in this study.

With only two validity studies conducted on the R-LPQ-2F using high school samples, it is clear that more research is needed to evaluate its psychometric properties. The R-LPQ-2F has also not yet been validated in the Singapore context. Though Kember et al.'s (2004) study was conducted in Hong Kong, where ethnic Chinese make up a majority of the population (similar to the Singapore context), Hong Kong and Singapore have very different educational systems and cultures (Yang \& Lin, 2009). It is thus possible that different results would be obtained across the two settings. The goal of the present study, therefore, was to examine the construct validity of the R-LPQ-2F in a sample of Singapore high school level students.

Based on the 2014 Standards for Educational and Psychological Testing (AERA, APA \& NCME, 2014), two types of validity evidence were examined in this study. First, the internal structure of the R-LPQ-2F was evaluated through CFAs which replicated those conducted by Kember et al. (2004) and Phan and Deo (2007). Internal consistencies and inter-correlations between the scales, subscales and components were also examined. Second, relationships between the R-LPQ-2F and two external variables: scores from the Motivation section of the Motivated Strategies for Learning Questionnaire (Pintrich, Smith, Garcia \& McKeachie, 1991, 1993) and academic performance, were investigated. Expected patterns of relationships between these variables are discussed in more detail in the Method section.

\section{Method}

\subsection{Participants}

Participants were 455 Year 11 students (266 male and 189 female) from a high school in Singapore. The average age of the participants was 16.7 years $(S D=0.39)$. The participants were enrolled in a two-year physics course taught in the English language, which would prepare them for the General Certificate of Education Advanced Level (GCE 'A' Level) physics examination. The latter examination is administered jointly by the Singapore 
Ministry of Education and the United Kingdom University of Cambridge International Examinations authority.

\subsection{Validation Instruments}

In addition to the R-LPQ-2F, two further instruments were used in the validation study. First, the Motivation section of the Motivated Strategies for Learning Questionnaire (MSLQ; Pintrich et al., 1991, 1993) was used. The MSLQ is a well-established instrument in the area of self-regulated learning (Duncan \& McKeachie, 2005). Studies of the psychometric properties of the MSLQ have generally produced favourable results. For example, Garcia and Pintrich (1995) demonstrated the sound psychometric properties of the MSLQ using data gathered from 380 students across 14 different subject domains. The Motivation section of the MSLQ includes six scales: Intrinsic Goal Orientation, Extrinsic Goal Orientation, Task Value, Control of Learning Beliefs, Self-efficacy for Learning and Performance, and Test Anxiety. There are a total of 31 item statements, to which students respond on a seven-point scale, ranging from 'not at all true of me' to 'very true of me'.

Table 3 summarizes the expected pattern of correlations between the R-LPQ-2F scales, subscales and components and the MSLQ motivation scales. Variables relating to deep learning are generally expected to show positive correlations with the 'positive' motivation constructs measured by the MSLQ (i.e., Intrinsic Goal Orientation, Control of Learning Beliefs and Self-efficacy for Learning and Performance) (e.g., Biggs \& Tang, 2011). Conversely, variables related to surface learning are expected to show negative correlations with the 'positive' motivation constructs in the MSLQ, and positive correlations with the 'negative' motivation constructs in the MSLQ (e.g., Curran \& Bowie, 1998).

Table 3. Expected pattern of correlations between the R-LPQ-2F, MSLQ, and achievement

\begin{tabular}{|c|c|c|c|c|c|c|c|}
\hline \multirow[t]{2}{*}{ R-LPQ-2F Variables } & $\begin{array}{l}\text { MSLQ } \\
\text { Variables }\end{array}$ & \multicolumn{2}{|c|}{ 'Positive' } & Motivation & \multicolumn{2}{|c|}{$\begin{array}{l}\text { MSLQ 'Negative' Motivation } \\
\text { Variables }\end{array}$} & \multirow{2}{*}{$\begin{array}{l}\text { Achieve-ment } \\
7\end{array}$} \\
\hline & 1 & 3 & 4 & 5 & 2 & 6 & \\
\hline Deep Approach & + & + & + & + & - & - & + \\
\hline Deep Motive & + & + & + & + & - & - & + \\
\hline Deep Strategy & + & + & + & + & - & - & + \\
\hline Intrinsic Interest (Deep) & + & + & + & + & - & - & + \\
\hline Commitment to Work (Deep) & + & + & + & + & - & - & + \\
\hline Relating Ideas (Deep) & + & + & + & + & - & - & + \\
\hline Understanding (Deep) & + & + & + & + & - & - & + \\
\hline Surface Approach & - & - & - & - & + & + & - \\
\hline Surface Motive & - & - & - & - & + & + & - \\
\hline Surface Strategy & - & - & - & - & + & + & - \\
\hline Fear of Failure (Surface) & - & - & - & - & + & + & - \\
\hline Aim for Qualification (Surface) & - & - & - & - & + & + & - \\
\hline $\begin{array}{l}\text { Minimizing Scope of Study } \\
\text { (Surface) }\end{array}$ & - & - & - & - & + & + & - \\
\hline Memorization (Surface) & - & - & - & - & + & + & - \\
\hline
\end{tabular}

Note. 1. Intrinsic Goal Orientation; 2. Extrinsic Goal Orientation; 3. Task Value; 4. Control of Learning Beliefs; 5. Self-efficacy for Learning and Performance; 6. Test Anxiety; 7. Physics Achievement Test.

Scores on the R-LPQ-2F were also correlated with physics achievement test scores. The Physics achievement test used in this study was a two-hour pen-and-paper assessment comprising 15 multiple-choice questions and 3 short response questions, adapted directly from past year GCE 'A' level examinations. The test questions, including the marking scheme, were vetted by the subject coordinator and the head of the physics department, who each had more than ten years of teaching experience, to ensure close alignment to the assessment objectives of the GCE ' $A$ ' level physics examination (Singapore Examinations and Assessment Board, 2014). The test scores were computed by summing the scores for the multiple-choice questions and the open-ended questions, with a maximum scores of 
15 and 65 respectively, giving a total maximum score of 80 . As indicated previously, deep learning is generally found to correlate positively with achievement scores, while surface learning has been found to correlate negatively with achievement. The expected pattern of correlations between the R-LPQ-2F and achievement is presented in Table 4.

Table 4. Descriptive Statistics for main scale, subscale and components of R-LPQ-2F

\begin{tabular}{lllll}
\hline \multirow{2}{*}{ Main Scale } & & Item Number & $\boldsymbol{M}$ & $\boldsymbol{S D}$ \\
\hline \multirow{5}{*}{ Subscale } & Deep Approach & $1,2,5,6,9,10,13,14,17,19,21$ & 3.26 & 0.59 \\
\cline { 2 - 5 } & Surface Approach & $3,4,7,8,11,12,15,16,18,20,22$ & 2.86 & 0.48 \\
\hline & Deep Motive & $1,5,9,13,17,19,21$ & 3.12 & 0.61 \\
\cline { 2 - 5 } & Deep Strategy & $2,6,10,14$ & 3.50 & 0.73 \\
\cline { 2 - 5 } Deep Motive Component & Surface Motive & $3,7,11,15$ & 3.70 & 0.68 \\
\cline { 2 - 5 } & Surface Strategy & $4,8,12,16,18,20,22$ & 2.38 & 0.57 \\
\hline \multirow{2}{*}{ Deep Strategy Component } & Intrinsic Interest & $1,5,9$ & 3.41 & 0.74 \\
\cline { 2 - 5 } & Commitment to Work & $13,17,19,21$ & 2.91 & 0.67 \\
\hline \multirow{2}{*}{ Surface Motive Component } & Relating Ideas & 2,6 & 3.32 & 0.90 \\
\cline { 2 - 5 } & Understanding & 10,14 & 3.68 & 0.76 \\
\hline \multirow{2}{*}{ Surface Strategy Component } & Fear of Failure & 3,7 & 3.41 & 0.97 \\
\cline { 2 - 5 } & Aim for Qualification & 11,15 & 3.99 & 0.76 \\
\hline & Minimizing Scope of Study & $4,8,12,16$ & 2.50 & 0.63 \\
\cline { 2 - 5 } & Memorization & $18,20,22$ & 2.21 & 0.73 \\
\hline
\end{tabular}

\subsection{Procedure}

Approval to conduct the research was first obtained from the Human Research Ethics Committee of the authors' research institution. Permission was also granted by the principal of the participating school. At the end of a three-month physics course unit on Newtonian mechanics, all participating students completed the R-LPQ-2F and the motivation section of the MSLQ in a single session. They were provided with hardcopies of the questionnaires and optical mark sheets to shade their responses. Prior to completing the R-LPQ-2F and MSLQ, students were told that their individual responses would not have any bearing on their course grades. In a separate session, they also completed the pen-and-paper closed book physics achievement test. They were given unique codes to use for the questionnaires as well as for the Physics Achievement Test answer scripts, so that their responses could be matched.

\section{Results and Discussion}

SPSS version 19 (IBM Corp, 2010) was used to generate all descriptive statistics, Cronbach $\alpha$ coefficients, and bivariate correlations, while LISREL 8.8 (Jöreskog \& Sörbom, 2006) was used to perform all CFAs within the study. Prior to conducting these analyses, screening tests for conformity to underlying CFA assumptions were conducted. These tests generally produced satisfactory results. Inspections of z-scores and Mahalanobis distances indicated no univariate or multivariate outliners within the set, at the .001 level. There was also no evidence of multicollinearity within the variable set, and no evidence of significant deviations from normality based on skewness or kurtosis coefficients.

Table 5 presents descriptive statistics for items in the R-LPQ-2F. As indicated, the average scores for the Deep Approach scale were higher than for the Surface Approach scale. Interestingly, average scores for Surface Motive were the highest amongst all of the subscales. The latter result was due primarily to the high average scores observed for the two Surface Motive components, Fear of Failure and Aim for Qualification. 
Table 5. Item descriptives for the R-LPQ-2F

\begin{tabular}{|c|c|c|c|c|c|}
\hline Scale & Subscale & Component & Item & $M$ & $S D$ \\
\hline \multirow{11}{*}{ Deep Approach } & \multirow{7}{*}{ Deep Motive } & \multirow{3}{*}{ Intrinsic Interest } & 1 & 3.39 & 0.96 \\
\hline & & & 5 & 3.58 & 0.94 \\
\hline & & & 9 & 3.25 & 0.89 \\
\hline & & \multirow{4}{*}{ Commitment to Work } & 13 & 2.59 & 1.02 \\
\hline & & & 17 & 2.86 & 0.90 \\
\hline & & & 19 & 2.73 & 1.08 \\
\hline & & & 21 & 3.47 & 0.92 \\
\hline & \multirow{4}{*}{ Deep Strategy } & \multirow{2}{*}{ Relating Ideas } & 2 & 3.46 & 0.95 \\
\hline & & & 6 & 3.19 & 1.14 \\
\hline & & \multirow{2}{*}{ Understanding } & 10 & 3.62 & 0.92 \\
\hline & & & 14 & 3.74 & 0.90 \\
\hline \multirow{11}{*}{ Surface Approach } & \multirow{4}{*}{ Surface Motive } & \multirow{2}{*}{ Fear of Failure } & 3 & 3.32 & 1.11 \\
\hline & & & 7 & 3.50 & 1.10 \\
\hline & & \multirow{2}{*}{ Aim for Qualification } & 11 & 3.96 & 0.90 \\
\hline & & & 15 & 4.02 & 0.86 \\
\hline & \multirow{7}{*}{ Surface Strategy } & \multirow{4}{*}{ Minimizing Scope of Study } & 4 & 2.57 & 0.95 \\
\hline & & & 8 & 2.32 & 1.05 \\
\hline & & & 12 & 2.92 & 0.89 \\
\hline & & & 16 & 2.21 & 0.92 \\
\hline & & \multirow{3}{*}{ Memorization } & 18 & 2.35 & 1.00 \\
\hline & & & 20 & 2.20 & 0.97 \\
\hline & & & 22 & 2.08 & 0.87 \\
\hline
\end{tabular}

\subsection{Evidence Based on Investigations of Internal Structure}

(a) Confirmatory Factor Analyses. CFAs were performed on two first-order models, replicating the analyses performed by Kember et al. (2004) and Phan and Deo (2007). Only first-order models were tested in this study. Three absolute fit indices (the Standardized Root Mean Square Residual, or SRMR; the relative chi-square value, or $\chi^{2} / \mathrm{df}$; and the Root Mean Square Error of Approximation, or RMSEA) and two relative fit indices (the Comparative Fit Index, or CFI, and the Non-Normed Fit Index, NNFI) were used to assess the fit of each model tested. Accepted cut-offs suggest that in CFAs, good model fit is indicated by a $\chi^{2} / \mathrm{df}<5$, SRMR $<0.08$, values greater than 0.90 for the CFI and NNFI (e.g., Browne \& Cudeck, 1993; Byrne, 1989; MacCallum, Browne \& Sugawara, 1996; Schumacker \& Lomax, 2004), and RMSEAs of between 0.01 (excellent fit) to 0.08 (adequate fit). The Goodness of Fit Index (GFI) was not used in this study, based on current recommendations within the field (Sharma, Mukherjee, Kumar \& Dillon, 2005). Differences between nested models within each of the MSLQ sections were evaluated using the chi square difference test (i.e., $\Delta \chi^{2}$ ). Three sets of models were tested:

- Models (a) and (b) were performed with all items within the instrument. Model (a) was a two-factor model, in which all items were grouped into their respective Surface and Deep Approach scales. Model (b) grouped items into the four subscales within the instrument (i.e., Surface Motive, Surface Strategy, Deep Motive, and Deep Strategy).

- Models (c), (d) and (e) were performed within the Deep Approach scale. Model (c) was a one-factor model for all Deep Approach scale items. Model (d) was a two-factor, with items grouped into their respective Deep Motive and Deep Strategy subscales. Model (e) was a four-factor model, with items grouped into their respective Deep Approach components: Intrinsic Interest, Commitment to Work, 
Relating Ideas, and Understanding.

- Models (f), (g) and (h) were performed within the Surface Approach scale. Model (f) was a one-factor model for all Surface Approach scale items. Model (g) was a two-factor model, with items grouped into their respective Surface Motive and Surface Strategy subscales. Model (h) was a four-factor, with items grouped into their respective Surface Approach components: Fear of Failure, Aim for Qualification, Minimizing Scope of Study, and Memorization.

The fit indices for the models are presented in Table 6 . As indicated, the fit indices for both of the overall scale models (i.e., Models (a) and (b)) approached, but did not meet, suggested criteria. These results contrast with the findings of Kember et al. (2004) and Phan and Deo (2007), who found adequate fit to their data for the overall two-factor model.

Table 6. Fit indices of first-order models

\begin{tabular}{|c|c|c|c|c|c|c|c|c|}
\hline Model & $\chi^{2}$ & $\mathrm{df}$ & $\chi^{2} / \mathrm{df}$ & SRMR & RMSEA & CFI & NNFI & $\Delta \chi^{2}$ statistics \\
\hline $\begin{array}{l}\text { (a) Two-factor (Deep and Surface } \\
\text { Approach Scales) }\end{array}$ & $1032.95^{*}$ & 208 & 4.97 & .096 & .10 & .81 & .79 & $\begin{array}{l}\text { (a) \& (b): } \Delta \chi^{2}(5)= \\
200.01, p<0.05\end{array}$ \\
\hline $\begin{array}{l}\text { (b) Four-factor (Deep and Surface } \\
\text { Approach Subscales) }\end{array}$ & $832.94 *$ & 203 & 4.10 & .085 & .09 & .86 & .84 & \\
\hline $\begin{array}{l}\text { (c) One-factor (Deep Approach } \\
\text { Scale) }\end{array}$ & $176.42 *$ & 44 & 4.00 & .050 & .08 & .95 & .94 & $\begin{array}{l}\text { (c) \& (d): } \Delta \chi^{2}(1)= \\
43.94, p<0.05\end{array}$ \\
\hline $\begin{array}{l}\text { (d) Two-factor (Deep Approach } \\
\text { Subscales) }\end{array}$ & $132.48 *$ & 43 & 3.08 & .044 & .07 & .97 & .96 & $\begin{array}{l}\text { (d) \& (e): } \Delta \chi^{2}(5)= \\
39.03, p<0.05\end{array}$ \\
\hline $\begin{array}{l}\text { (e) Four-factor (Deep Approach } \\
\text { Components) }\end{array}$ & $93.45^{*}$ & 38 & 2.46 & .036 & .05 & .98 & .97 & $\begin{array}{l}\text { (e) \& (c): } \Delta \chi^{2}(6)= \\
82.97, \mathrm{p}<0.05\end{array}$ \\
\hline $\begin{array}{l}\text { (f) One-factor (Surface Approach } \\
\text { Scale) }\end{array}$ & $480.08^{*}$ & 44 & 10.91 & .110 & .16 & .66 & .58 & $\begin{array}{l}\text { (f) \& (g): } \Delta \chi^{2}(1)= \\
143.87, \mathrm{p}<0.05\end{array}$ \\
\hline $\begin{array}{l}\text { (g) Two-factor (Surface Approach } \\
\text { Subscales) }\end{array}$ & $336.21 *$ & 43 & 7.81 & .098 & .13 & .77 & .71 & $\begin{array}{l}\text { (g) \& (h): } \Delta \chi^{2}(5)= \\
181.24, \mathrm{p}<0.05\end{array}$ \\
\hline $\begin{array}{l}\text { (h) Four-factor (Surface Approach } \\
\text { Components) }\end{array}$ & $154.97 *$ & 38 & 4.08 & .075 & .09 & .91 & .87 & $\begin{array}{l}\text { (h) \& (f): } \Delta \chi^{2}(6)= \\
325.11, p<0.05\end{array}$ \\
\hline
\end{tabular}

* Significant at $\alpha=.05$ level.

As indicated in Table 6, Models (c), (d) and (e) for the Deep Approach scale all indicated good fit to the data. Given that the fit indices for the more parsimonious one-factor model were adequate, a one-factor model was deemed most appropriate for the Deep Approach Scale. In contrast, Models (f), (g) and (h) for the Surface Approach Scale indicate that neither the one- nor the two-factor model fit the data well. The four-factor model fit significantly better than the two-factor model, and only this four-factor model meet the fit cut-offs on most criteria (i.e., $\chi^{2} / \mathrm{df}$, SRMR, RMSEA and CFI). Similar to the results of the Phan and Deo (2007) study, however, the NNFI for the latter model still fell slightly below the accepted cut-off of .90 .

Taken together, the most parsimonious model of the R-LPQ-2F that provided adequate data fit in the current study was the one-factor model for the deep learning scale, and the four-factor model for the surface learning scale (Fear of Failure, Aim for Qualification, Minimizing Scope of Study, and Memorization). The final factor models of the Deep Approach and Surface Approach scales are presented in Figures 1 and 2 (respectively). These results suggest that, in the Singapore high school sample, while the Deep Approach scale could be considered unidimensional, the Surface Approach scale could not. 


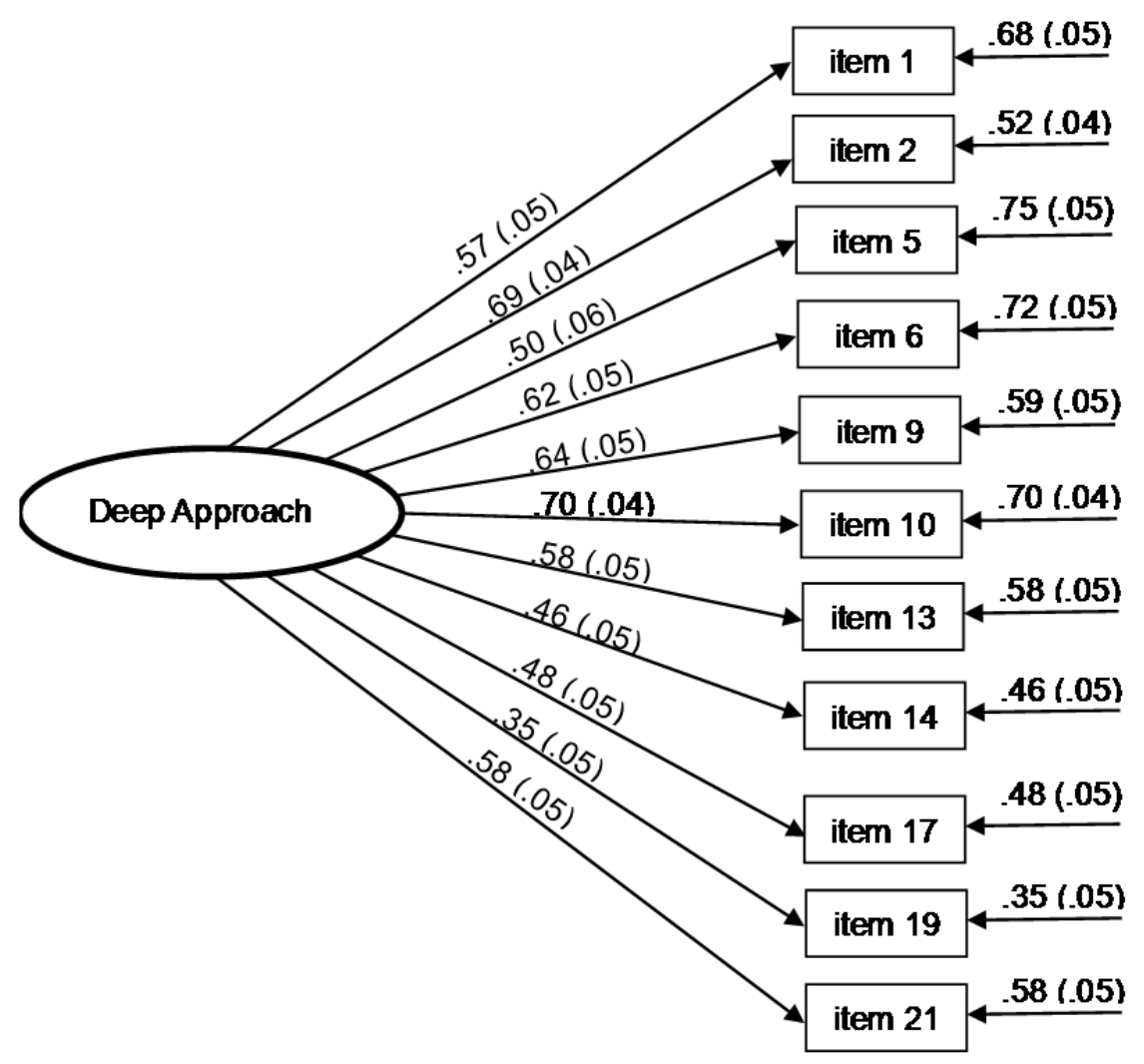

Figure 1. Final one-factor model for the Deep Approach Scale

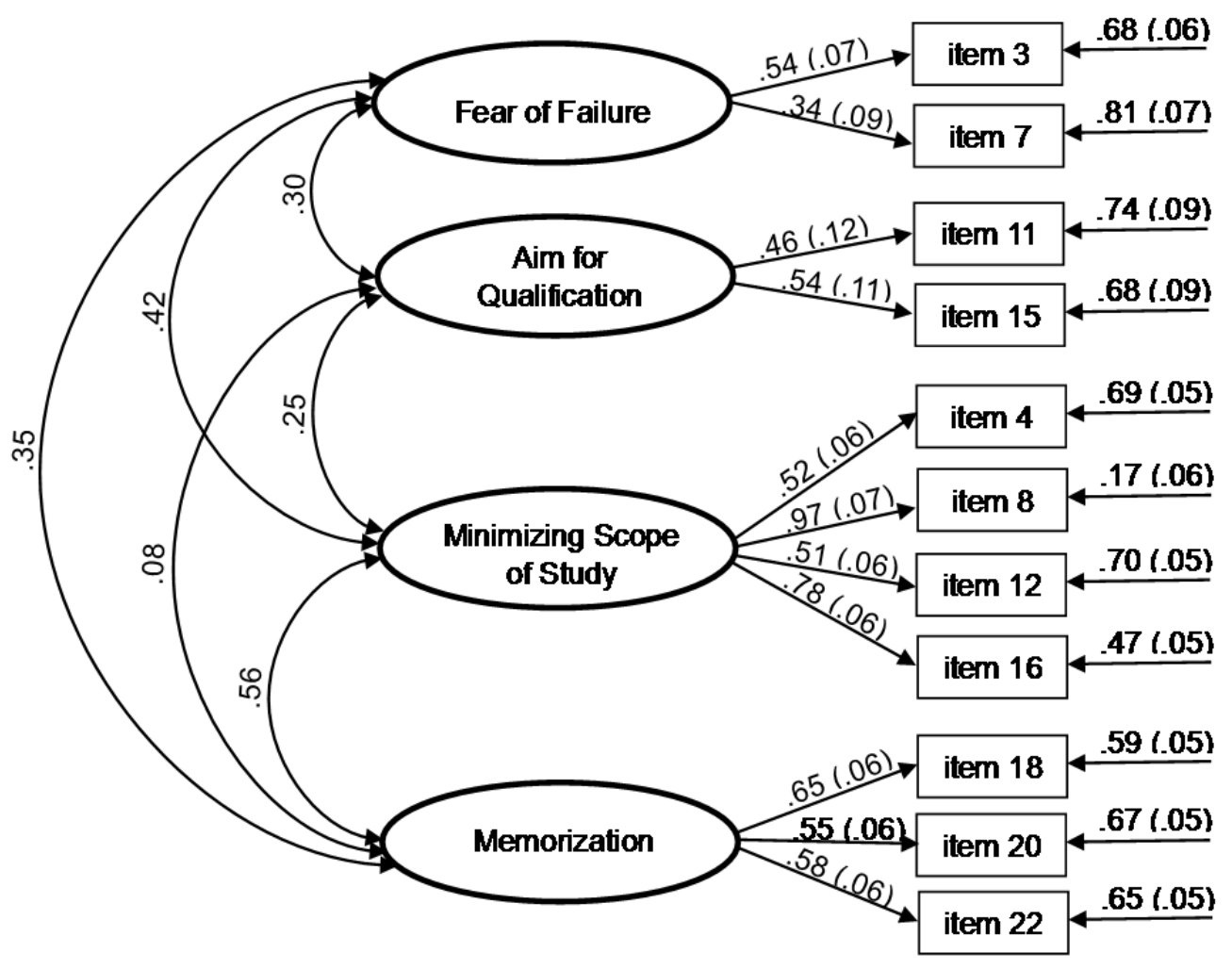

Figure 2. Final four-factor model for the Surface Approach Scale 
(b) Internal Consistencies. Cronbach $\alpha$ coefficients (Cronbach, 1970) for the main scales, subscales and components of the R-LPQ-2F are presented in Table 7, together with the findings by Kember et al. (2004) and Phan and Deo (2007). As indicated, the two main scales and most of the subscales achieved sound internal consistencies, and even the components had reasonable coefficients, despite having a small number of items. The $\alpha$ coefficients in the current study were also observed to be generally higher than those in the other two studies conducted by Kember et al. and Phan and Deo.

Table 7. Cronbach $\alpha$ coefficients for the R-LPQ-2F

\begin{tabular}{|c|c|c|c|c|c|c|}
\hline & & & $\begin{array}{l}\text { No. of } \\
\text { Items }\end{array}$ & $\begin{array}{l}\text { Current } \\
\text { Study }\end{array}$ & $\begin{array}{l}\text { Kember et al.'s } \\
(2004) \text { study }\end{array}$ & $\begin{array}{l}\text { Phan and Deo's } \\
(2007) \text { study }\end{array}$ \\
\hline \multirow{2}{*}{\multicolumn{2}{|c|}{ Main Scale }} & Deep Approach & 11 & .84 & .82 & .70 \\
\hline & & Surface Approach & 11 & .70 & .71 & .62 \\
\hline \multirow{4}{*}{\multicolumn{2}{|c|}{ Subscale }} & Deep Motive & 7 & .75 & .75 & .58 \\
\hline & & Deep Strategy & 4 & .74 & .66 & .54 \\
\hline & & Surface Motive & 4 & .61 & .58 & .42 \\
\hline & & Surface Strategy & 7 & .70 & .68 & .53 \\
\hline \multirow{2}{*}{$\begin{array}{l}\text { Deep } \\
\text { Component }\end{array}$} & \multirow[t]{2}{*}{ Motive } & Intrinsic Interest & 3 & .83 & .59 & -- \\
\hline & & Commitment to Work & 4 & .62 & .70 & -- \\
\hline \multirow{2}{*}{$\begin{array}{l}\text { Deep } \\
\text { Component }\end{array}$} & \multirow[t]{2}{*}{ Strategy } & Relating Ideas & 2 & .65 & .48 & -- \\
\hline & & Understanding & 2 & .55 & .59 & -- \\
\hline \multirow{2}{*}{$\begin{array}{l}\text { Surface } \\
\text { Component }\end{array}$} & \multirow[t]{2}{*}{ Motive } & Fear of Failure & 2 & .71 & .65 & -- \\
\hline & & Aim for Qualification & 2 & .66 & .63 & -- \\
\hline \multirow{2}{*}{$\begin{array}{l}\text { Surface } \\
\text { Component }\end{array}$} & \multirow[t]{2}{*}{ Strategy } & $\begin{array}{l}\text { Minimizing Scope of } \\
\text { Study }\end{array}$ & 4 & .56 & .52 & -- \\
\hline & & Memorization & 3 & .66 & .55 & -- \\
\hline
\end{tabular}

(c) Intercorrelations within the scale. Intercorrelations for the R-LPQ-2F scales, subscales and components are presented in Table 8. As indicated, Deep and Surface Approach scores were not significantly correlated, in contrast to the results reported by Kember et al. (2004), who found modest levels of positive correlation between these two broad scales. This finding suggests that for Singapore high school students, deep and surface approaches may not represent two opposing ends of a continuum, as is commonly perceived. It may, therefore, be possible for students to concurrently adopt different learning approaches for a particular learning task. It is also noted that Deep Motive and Deep Strategy scores were highly correlated, as would be expected, but the correlation between Surface Motive and Surface Strategy was only modest.

Table 8. Intercorrelations of the R-LPQ-2F main scales and subscales

\begin{tabular}{lllllll}
\hline Scale / Subscale & 1 & 2 & 3 & 4 & 5 & 6 \\
\hline $1 . \quad$ Deep Approach & - & .04 & $.94^{* *}$ & $.87^{* *}$ & $.17^{* *}$ & -.06 \\
2. Surface Approach & & - & .06 & .01 & $.68^{* *}$ & $.87^{* *}$ \\
3. Deep Motive & & & - & $.64^{* *}$ & $.16^{* *}$ & -.03 \\
4. Deep Strategy & & & & - & $.15^{* *}$ & -.09 \\
$5 . \quad$ Surface Motive & & & - & $.22^{* *}$ \\
$6 . \quad$ Surface Strategy & & & & - \\
\hline$* p<.05, * * p<.01$. & & & &
\end{tabular}


Table 9 shows the intercorrelations between the components of the R-LPQ-2F. Components 1 and 2 relate to Deep Motive; 3 and 4 to Deep Strategy; 5 and 6 to Surface Motive; and 7 and 8 to Surface Strategy. The correlations between the deep learning components (1-4) were positive and relatively high, as expected. With the exception of Aim for Qualification, the surface learning components (5-8) also exhibited similar patterns of correlations, albeit weaker.

Table 9. Intercorrelations between the R-LPQ-2F components

\begin{tabular}{|c|c|c|c|c|c|c|c|c|}
\hline Component & 1 & 2 & 3 & 4 & 5 & 6 & 7 & 8 \\
\hline 1. Intrinsic Interest (Deep Motive) & - & $.50 * *$ & $.47 * *$ & $.45^{* *}$ & .03 & $.18^{* *}$ & $-.19 * *$ & -.02 \\
\hline 2. Commitment to Work (Deep Motive) & & - & $.53 * *$ & $.48 * *$ & $.12 *$ & $.11^{*}$ & -.05 & $.13 * *$ \\
\hline 3. Relating Ideas (Deep Strategy) & & & - & $.56^{* *}$ & .01 & .09 & -.07 & -.04 \\
\hline 4. Understanding (Deep Strategy) & & & & - & .09 & $.28^{* *}$ & $-.14 * *$ & -.04 \\
\hline 5. Fear of Failure (Surface Motive) & & & & & - & $.21 * *$ & $.22 * *$ & $.24 * *$ \\
\hline 6. Aim for Qualification (Surface Motive) & & & & & & - & .03 & .06 \\
\hline 7. Minimizing Scope of Study (Surface Strategy) & & & & & & & - & $.43 * *$ \\
\hline 8. Memorization (Surface Strategy) & & & & & & & & - \\
\hline
\end{tabular}

$* p<.05, * * p<.01$.

In the theoretical framework of the R-LPQ-2F, Aim for Qualification and Fear of Failure, which are classified as surface motives, are perceived to be undesirable because these are likely to lead to the use of surface cognitive strategies, and consequently, to poorer academic outcomes (Biggs, 1993). While the results of this study similarly indicate that Fear of Failure was associated with greater use of surface strategies, Aim for Qualification was not significantly correlated with the Surface Strategy variables. Instead, it correlated positively with two deep motive components (Intrinsic Interest and Commitment to Work) and one deep strategy component (Understanding). These results, therefore, suggest that aspiring for a higher qualification may not be associated with negative outcomes in the Singapore high school context.

\subsection{Evidence Based on Relationships with External Variables}

Correlations between the R-LPQ-2F and scores on the MSLQ Motivation scales, and Physics Achievement Test scores are presented in Table 10. As expected, the Deep Approach scale, subscale, and component scores all correlated positively with the 'positive' MSLQ motivation scale scores. With the exception of two components (Commitment to Work and Relating Ideas), all the Deep Approach variables also correlated positively with physics achievement. Surprisingly, the MSLQ Extrinsic Goal Orientation scale correlated positively with all of the Deep Approach variables, and similarly, the MSLQ Test Anxiety scores also correlated positively with the Deep Approach scale score, as well as with Deep Motive and Commitment to Work scores. The latter two sets of results are surprising, given that both Extrinsic Goal Orientation and Test Anxiety are generally perceived to represent 'negative' aspects of motivation. The results are, however, aligned with results reported by Pintrich and Garcia (1991), who found evidence that deep learning can be associated with higher levels of extrinsic motivation. It might also reflect the influence of Confucius Heritage Culture (CHC) of Singapore, which places great emphasis on academic performance and qualifications, as well as the acquisition of deep knowledge (for a more comprehensive review of the CHC, see Watkins \& Biggs, 1996). 
Table 10. Correlations of R-LPQ-2F with MSLQ motivation variables and Physics Achievement Test scores

\begin{tabular}{|c|c|c|c|c|c|c|c|}
\hline \multirow{2}{*}{$\begin{array}{l}\text { R-LPQ-2F } \\
\text { Variables }\end{array}$} & \multicolumn{4}{|c|}{ MSLQ 'Positive’ Motivations } & \multicolumn{2}{|l|}{$\begin{array}{l}\text { MSLQ } \\
\text { Motivations }\end{array}$} & \multirow{2}{*}{$\begin{array}{l}\text { Physics } \\
\text { Achieve-ment }\end{array}$} \\
\hline & $\begin{array}{l}\text { Intrinsic } \\
\text { Goal } \\
\text { Orientation }\end{array}$ & $\begin{array}{l}\text { Task } \\
\text { Value }\end{array}$ & $\begin{array}{l}\text { Control of } \\
\text { Learning } \\
\text { Beliefs }\end{array}$ & $\begin{array}{l}\text { Self-efficacy of } \\
\text { Learning and } \\
\text { Perf }\end{array}$ & $\begin{array}{l}\text { Extrinsic } \\
\text { Goal } \\
\text { Orien-tation }\end{array}$ & $\begin{array}{l}\text { Test } \\
\text { Anxiety }\end{array}$ & \\
\hline Deep Approach & $.61 * *$ & $.66^{* *}$ & $.46^{* *}$ & $.53^{* *}$ & $.33^{* *}$ & $.12 *$ & $.12 *$ \\
\hline Deep Motive & $.57 * *$ & $.60 * *$ & $.41 * *$ & $.46^{* *}$ & $.35 * *$ & $.14 * *$ & $.09 *$ \\
\hline Deep Strategy & $.53 * *$ & $.59^{* *}$ & $.42 * *$ & $.50 * *$ & $.23 * *$ & .05 & $.13^{* *}$ \\
\hline Intrinsic Interest & $.55 * *$ & $.58 * *$ & $.39 * *$ & $.41 * *$ & $.27 * *$ & .04 & $.10^{*}$ \\
\hline $\begin{array}{l}\text { Commitment to } \\
\text { Work }\end{array}$ & $.45 * *$ & $.47 * *$ & $.32 * *$ & $.40 * *$ & $.34 * *$ & $.19 * *$ & .07 \\
\hline Relating Ideas & $.51 * *$ & $.49 * *$ & $.33 * *$ & $.44 * *$ & $.17 * *$ & .02 & .10 \\
\hline Understanding & $.43 * *$ & $.57 * *$ & $.43 * *$ & $.45^{* *}$ & $.23 * *$ & .07 & $.13 * *$ \\
\hline $\begin{array}{l}\text { Surface } \\
\text { Approach }\end{array}$ & $-.23 * *$ & $-.10 *$ & .01 & $-.16^{* *}$ & $.42 * *$ & $.50 * *$ & $-.15^{* *}$ \\
\hline Surface Motive & -.01 & $.20 * *$ & $.23 * *$ & -.05 & $.48 * *$ & $.58 * *$ & -.08 \\
\hline $\begin{array}{l}\text { Surface } \\
\text { Strategy }\end{array}$ & $-.29 * *$ & $-.26^{* *}$ & $-.15^{* *}$ & $-.17 * *$ & $.22 * *$ & $.27 * *$ & $-.15 * *$ \\
\hline Fear of Failure & -.06 & .08 & $.10^{*}$ & $-.16 * *$ & $.35 * *$ & $.70 * *$ & $-.12 *$ \\
\hline $\begin{array}{l}\text { Aim for } \\
\text { Qualification }\end{array}$ & .06 & $.25^{* *}$ & $.29 * *$ & $.10^{*}$ & $.41 * *$ & $.14 * *$ & .02 \\
\hline $\begin{array}{l}\text { Minimizing } \\
\text { Scope of Study }\end{array}$ & $-.34 * *$ & $-.29 * *$ & $-.12 * *$ & $-.15^{* *}$ & $.14 * *$ & $.20 * *$ & $-.12 *$ \\
\hline Memorization & $-.15 * *$ & $-.15 * *$ & $-.14 * *$ & $-.14 * *$ & $.25 * *$ & $.27 * *$ & $-.15 * *$ \\
\hline
\end{tabular}

${ }^{*} p<.05, * * p<.01$.

Results for the overall Surface Approach scale and the Surface Strategy subscale and component scores were also generally aligned with expectations. Surface Approach scale scores correlated negatively with three of the four positive MSLQ motivation variables (Intrinsic Goal Orientation, Task Value, and Self-Efficacy for Learning and Performance) and with physics achievement, but positively with the two negative MSLQ motivation variables (Extrinsic Goal Orientation and Test Anxiety). Surface strategy subscale scores and the two components of Surface Strategy, Minimising Scope of Study and Memorization, correlated negatively with all positive MSLQ variables and with physics achievement, while correlating negatively with the two positive MSLQ motivation variables of Extrinsic Goal orientation and Test Anxiety.

In contrast, the patterns of correlation obtained for Surface Motive and the two components of Surface Motive (Fear of Failure and Aim for Qualification) did not align well with expectations. While all three variables did correlate positively with the two negative MSLQ variables, amongst the three, only Fear of Failure was negatively correlated with physics achievement. Fear of Failure was also, as expected, negatively correlated with Self-Efficacy for Learning and Performance. Surprisingly, however, both Surface Motive and Aim for Qualification were positively correlated with two of the positive MSLQ motivation scales (Task Value and Control of Learning Beliefs). Aim for Qualification was also positively correlated with Self-Efficacy for Learning and Performance. Thus, of the Surface components, the one that exhibited the most unexpected pattern was Aim for Qualification.

\section{Conclusions and Implications}

Results of this study indicate that the internal structure of the R-LPQ-2F in Singapore secondary students is similar to the original factor structure proposed by Kember et al. (2004). In this study, a structure comprising one deep factor and four surface factors fit the data well. Cronbach's $\alpha$ coefficients for the scales, subscales and components were generally also acceptable. Results of the intercorrelations within the R-LPQ-2F also supported the validity of 
the instrument. As the R-LPQ- $2 \mathrm{~F}$ is readily available and relatively brief, it provides an attractive option for educators to use in their ongoing practices. The results of this study affirm that the instrument is suitable for assessing students' learning approaches within Singapore classrooms.

Results of the correlations between the R-LPQ-2F Deep Approach scale and for the Surface Strategy subscale, MSLQ motivation scores, and physics achievement scores, similarly aligned with expectations derived from the theoretical basis of the R-LPQ-2F. This was not so, however, for the relationships between the Surface Motive subscale, MSLQ motivation, and physics achievement scores. This can be attributed primarily to the contribution of the Aim for Qualification component of the Surface Motive subscale. While these results were not expected based on previous results reported from Western countries, they do align well with emerging views of the surface and deep motivations held by many Asian students. For example, Boekaerts (2003) argued that, in contrast to Western cultures, factors such as personal ambition and material reward will prompt many Chinese students to adopt deep learning strategies. Ramburuth and McCormick (2001) similarly reported that Asian students will often combine surface strategies with intrinsic or deep motivations in approaching their learning tasks. Based on these results, assumptions made about the negative implications of motivations classed as 'surface' oriented in Western countries may not hold in Asian samples.

Future research is needed to investigate implications of the Surface Motive components of the instrument within the Singapore context. It should be noted here also that this study only focused on upper secondary level students. Thus, it is not known based on these results whether the instrument can be used in other levels of the Singapore system. Given its potential utility in this context, further work could also be conducted to determine the suitability of the R-LPQ-2F in earlier grade levels.

Overall, the results of this study provide strong support for the R-LPQ-2F to assess students' learning approaches in Singapore secondary schools. While many teachers may already be adopting strategies to encourage the use of deep learning approaches in their classrooms, it is possible that they are not effectively monitoring the progress of their students in this domain. The R-LPQ-2F can be a very useful tool for such a purpose. This instrument has various other advantages, which make it highly suitable for use in classroom contexts, which include the fact that it is readily downloadable online, free to use, and, with only 22 items, efficient to administer and score. Collectively, these features suggest that the R-LPQ-2F has considerable potential as a tool to monitor students' learning processes, with the ultimate goal of enhancing overall schooling outcomes.

\section{References}

AERA, APA, \& NCME (2014). Standards for educational and psychological testing. Washington, D.C.: Author.

Biggs, J. (1987). Student approaches to learning and studying. Melbourne: Australian Council for Educational Research.

Biggs, J. (1993). What do inventories of students' learning processes really measure? A theoretical review and $\begin{array}{lllll}\text { clarification. British Journal of Educational Psychology, } & \text { 63, } & \text { 1-17. }\end{array}$ https://doi.org/10.1111/j.2044-8279.1993.tb01038.x

Biggs, J. (1999). What the student does: Teaching for quality learning at university. Buckingham: Open University Press.

Biggs, J., \& Tang, C. (2011). Teaching for quality learning at university (4th ed.). Berkshire, UK: Open University Press.

Browne, M. W., \& Cudeck, R. (1993). Alternative ways of assessing model fit. In: K. A. Bollen \& J. S. Long (Eds.) Testing structural equation models (pp. 136-162). Beverly Hills, CA: Sage. https://doi.org/10.1177/0049124192021002005

Boekaerts, M. (2003). How do students from different cultures motivate themselves for academic learning? In F. Salili \& R. Hoosain (Eds.), Democracy and Multicultural Education. Charlotte, NC: Information Age Publishing.

Byrne, B. M. (1989). A primer of LISREL: Basic applications and programming for confirmatory factor analytic models. New York: Springer-Verlag.

Campbell, J., Smith, D., Boulton-Lewis, G., Brownlee, J., Burnett, P., Carrington, S., \& Purdie, N. (2001). Students' perceptions of teaching and learning: the influence of students' approaches to learning and teachers' approaches to teaching. Teachers and Teaching: Theory and Practice, 7(2), 173-187. https://doi.org/10.1080/13540600120054964 
Cano, F. (2005). Epistemological beliefs and approaches to learning: their change through secondary school and their influence on academic performance. British Journal of Educational Psychology, 75, $203-221$. https://doi.org/10.1348/000709904x22683

Cronbach, L. J. (1970). Essentials of psychological testing (3rd ed.). New York: Harper \& Row.

Curran, S., \& Bowie, P. (1998). Teaching psychiatry to medical undergraduates. Advances in Psychiatric Treatment, 4, 167-171. https://doi.org/10.1192/apt.4.3.167

Duncan, T. G., \& McKeachie, W. C. (2005). The making of the Motivated Strategies for Learning Questionnaire. Educational Psychologis, 40, 117-128. https://doi.org/10.1207/s15326985ep4002_6

Entwistle, N. (1988). Styles of Learning and Teaching. London: David Fulton.

Garcia, T., \& Pintrich, P. R. (1995). Assessing students' motivation and learning strategies: The Motivated Strategies for Learning Questionnaire (MSLQ). Paper presented at the Annual Meeting of the American Educational Research Association. San Francisco, CA: ERIC Document Reproduction Service No. ED 383 770. Retrieved from ERIC database.

Goh, C. T. (1997). Speech by prime minister Goh Chok Tong at the Opening of $7^{\text {th }}$ International Conference on Thinking, Singapore. Retrieved from http://www.moe.gov.sg/media/speeches/1997/020697.htm

IBM Corp. (2010). IBM SPSS Statistics for Windows, Version 19.0. Armonk, NY: IBM Corp.

Jöreskog, K. G., \& Sörbom, D. (2006). LISREL 8.8 for Windows [Computer Software]. Lincolnwood, IL: Scientific Software International, Inc.

Kember, D., Biggs, J., \& Leung, D. Y. (2004). Examining the multidimensionality of approaches to learning through the development of a revised version of the Learning Process Questionnaire. British Journal of Educational Psychology, 74, 261-280. https://doi.org/10.1348/000709904773839879

Kember, D., \& Gow, L. (1991). A challenge to the anecdotal stereotype of the Asian student. Studies in Higher Education, 16, 117-128. https://doi.org/10.1080/03075079112331382934

Kline, P. (2000). The handbook of psychological testing (2nd ed.). London: Routledge.

MacCallum, R. C., Browne, M. W., \& Sugawara, H. M. (1996). Power analysis and determination of sample size for covariance structure modeling. Psychological Methods, 1, 130-149. https://doi.org/10.1037/1082-989X.1.2.130

Marton, F., Hounsell, D., \& Entwistle, N. (1997). The experience of learning. Edinburgh: Scottish Academic Press.

Marton, F., \& Säljö, R. (1976). On qualitative differences in learning I: Outcome and process. British Journal of Educational Psychology, 46, 4-11. https://doi.org/10.1111/j.2044-8279.1976.tb02980.x

Nelson Laird, T., Shoup, R., Kuh, G., \& Schwarz, M. (2008). The effects of discipline on deep approaches to student learning and college outcomes. Research in Higher Education, 49(6), 469-494.

O'Day, J., \& Garet, M. S. (2014). The shape of deeper learning: strategies, structures, and cultures in deep learning network high $\quad$ schools. $\quad$ Retrieved from http://www.air.org/sites/default/files/downloads/report/Report\%201\%20The\%20Shape\%20of\%20Deeper\% 20Learning_9-23-14v2.pdf

Phan, H. P. (2007). An examination of reflective thinking, learning approaches, and self - efficacy beliefs at the university of the south pacific: A path analysis approach. Educational Psychology, 27, 789-806.

Phan, H. P. (2011). Deep processing strategies and critical thinking: Developmental trajectories using latent growth analyses. The Journal of Educational Research, 104, 283-294.

Phan, H. P., \& Deo, B. (2007). The revised learning questionnaire: A validation of a Western model of students' study approaches to the South Pacific context using confirmatory factor analysis. British Journal of Educational Psychology, 77, 719-739. https://doi.org/10.1348/000709906X158339

Pintrich, P. R., \& Garcia, T. (1991). Student goal orientation and self-regulation in the college classroom. In M. Maehr \& P.R. Pintrich (Eds.). Advances in Motivation and Achievement Goals and self-regulatory processes, 7. Greenwich: CT: JAI Press.

Pintrich, P. R., Smith, D. A., Garcia, T., \& McKeachie, W. J. (1991). A manual for the use of the Motivated Strategies for Learning Questionnaire (MSLQ). Ann Arbor: Michigan, National Centre for Research to Improve Postsecondary Teaching and Learning. 
Pintrich, P. R., Smith, D. A., Garcia, T., \& McKeachie, W. J. (1993). Reliability and predictive validity of the Motivated Strategies for Learning Questionnaire (MSLQ). Educational and Psychological Measurement, 53, 801-813. https://doi.org/10.1177/0013164493053003024

Pratt, D. D., \& Wong, K. M. (1999). Chinese conceptions of "effective teaching" in Hong Kong: Towards culturally sensitive evaluation of teaching. International Journal of Lifelong Education, 18, 241-258. https://doi.org/10.1080/026013799293739a

Ramburuth, P., \& McCormick, J. (2001). Learning diversity in higher education: A comparative study of Asian international and Australian students. Higher Education, 42(3), 333-350. https://doi.org/10.1023/A:1017982716482

Ramsden, P. (2003). Learning to teach in higher education (2nd ed.). London and New York: Routledge Falmer.

Rajah, I. (2013). Opening address at the Fifth Redesigning Pedagogy International Conference, Singapore. Retrieved

from http://www.moe.gov.sg/media/speeches/2013/06/03/speech-by-ms-indranee-rajah-at-the-opening-ceremony -of-the-fifth-redesigning-pedagogy-international-conference.php

Samuelowicz, K. (1987). Learning problems of overseas students: Two sides of a story. Higher Education Research and Development, 6, 121-134. https://doi.org/10.1080/0729436870060204

Singapore Examinations and Assessment Board. (2014). Singapore-Cambridge GCE A-Level Physics Higher 2 Syllabus $9646 . \quad$ Retrieved from https://www.seab.gov.sg/content/syllabus/alevel/2015Syllabus/9646_2015.pdf

Schumacker, R. E., \& Lomax, R. G. (2004). A beginner's guide to structural equation modeling (2nd ed.). Mahwah, NJ: Lawrence Erlbaum Associates.

Sharma, S., Mukherjee, S., Kumar, A., \& Dillon, W.R. (2005). A simulation study to investigate the use of cutoff values for assessing model fit in covariance structure models. Journal of Business Research, 58, 935-43. https://doi.org/10.1016/j.jbusres.2003.10.007

Watkins, D., \& Biggs, J. (1996) The Chinese learner: Cultural, psychological, and contextual influences (pp. 69-84). Hong Kong: Comparative Education Research Center.

Yang, M., \& Lin, S. (2009). Many Chinese cultures, many learning styles. In F. Fallon (Ed.), 20th ISANA International Education Association Conference proceedings (pp. 1-6). Hotel Realm, Canberra, Australia, 1-4 December 2009.

\section{Copyrights}

Copyright for this article is retained by the author(s), with first publication rights granted to the journal.

This is an open-access article distributed under the terms and conditions of the Creative Commons Attribution license (http://creativecommons.org/licenses/by/4.0/). 